\title{
Investigation of Benefit of Applying Handheld Scanner to Measure Tree Height and Diameter at Breast Height
}

\author{
Joon Kyu Park ${ }^{1}$ and Dae Yong $\mathrm{Um}^{2 *}$ \\ ${ }^{1}$ Department of Civil Engineering, Seoil University, 28, Yongmasan-ro 90-gil, Jungnang-gu, Seoul, Korea \\ ${ }^{2}$ Department of Civil Engineering, Korea National University of Transportation, \\ 50, Daehak-ro, Chungju-si, Chungbuk, Korea
}

(Received February 28, 2020; accepted June 19, 2020)

Keywords: diameter at breast height, laser scanner, felled tree, forest, handheld scanner, point cloud, measurement

Recently, several countries have established a national forest survey and monitoring system to analyze the exact amount of forest resources and identify changes in forest ecosystems. South Korea is also collecting data on basic forest statistics and conducting surveys to assess the health of forests. The most basic part of a forest survey has many subsequent effects in related work and in the work of actual measurers and information users. Therefore, accurate results are important because these results are the basis for the development of forest-related research. The diameter at breast height (DBH) is a measurement item for forest investigation, and it is the most basic data among the essential items of forest management, forest inventory, and carbon cycle modeling. DBH measurements have traditionally been made manually using calipers. However, this method can cause errors depending on the person and has a disadvantage that it is difficult to measure DBH when the shape of the tree is irregular. In existing forest research, there is a lack of research on this measurement method. As an emerging technology, 3D laser scanning has been introduced in the field of forestry, and its use is expected. In this study, a 3D laser scanner was used to measure DBH and tree height. Data on the forest studied were obtained using a handheld scanner. Software measurements were also performed on felled trees to obtain data, which were compared with those obtained using calipers. The DBH measurements showed a deviation of less than $4 \mathrm{~cm}$ from the caliper measurements. These results indicate that $\mathrm{DBH}$ can be measured using a handheld scanner. Also, measuring a tree diameter at a height of $1.2 \mathrm{~m}$ is difficult in the field; thus, using a handheld scanner will improve work efficiency. The tree heights measured using a handheld scanner were within $10 \mathrm{~cm}$ of the reference values. Although the reference values were measured using a total station for accurate measurement, an error is likely to occur when using a clinometer in the field, and tree height measurement using a handheld scanner may improve the measurement accuracy. Also, the diameters of felled trees were measured. The diameters of the felled trees measured using a scanner showed a difference of less than $4 \mathrm{~cm}$ from the reference values. There is a slight difference from the values measured using calipers or a tape, which may be due to the noise of

*Corresponding author: e-mail: dyum@ut.ac.kr https://doi.org/10.18494/SAM.2020.2847 
the point cloud. If further research is performed to reduce noise and automate the measurement, it may be possible to use a scanner-based method to measure the diameters of felled trees.

\section{Introduction}

Many countries have recently established a national forest survey and monitoring system to analyze the exact amount of forest resources and identify changes in forest ecosystems. ${ }^{(1-3)}$ In Korea, a national forest resource survey is conducted to obtain basic data on forest statistics and assess the health of forest ecosystems. ${ }^{(4-7)}$ The most basic part of a forest survey consists of several measurement tasks in the forest. ${ }^{(8-10)}$ In forestry, measurement generally involves measuring, for example, the size and range of a tree using an instrument. These measures provide information about the collective concept of forests. ${ }^{(11-14)}$ Such information has many subsequent effects in related work and in the work of actual measurers and information users. ${ }^{(15-17)}$ Therefore, accurate results are important because these results are the basis for the development of forest-related research. The diameter at breast height $(\mathrm{DBH})$ is the diameter of a tree measured at a height of $1.2 \mathrm{~m}$. This is a measurement item for forest investigation, and it is the most basic data among the essential items of forest management, forest inventory, and carbon cycle modeling. ${ }^{(18,19)}$ Figure 1 shows the concept of DBH and Fig. 2 shows an example of a carbon cycle model.

DBH measurements have traditionally been made manually using calipers. However, this method can cause errors depending on the person and has a disadvantage that it is difficult to measure DBH when the shape of the tree is irregular. Figure 3 shows traditional DBH measurement.

The tree height, together with $\mathrm{DBH}$, is one of the most important factors determining the volume of trees, so precise and accurate measurements are required. In practice, the tree height

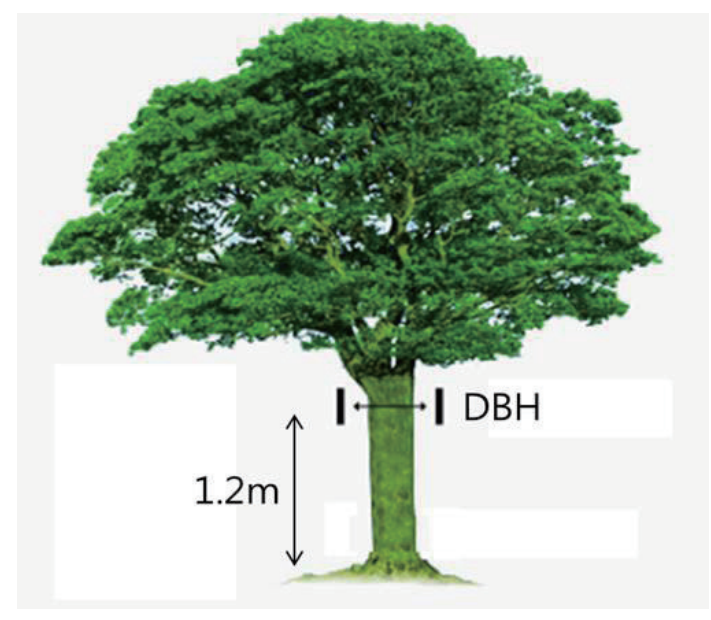

Fig. 1. (Color online) Concept of DBH.

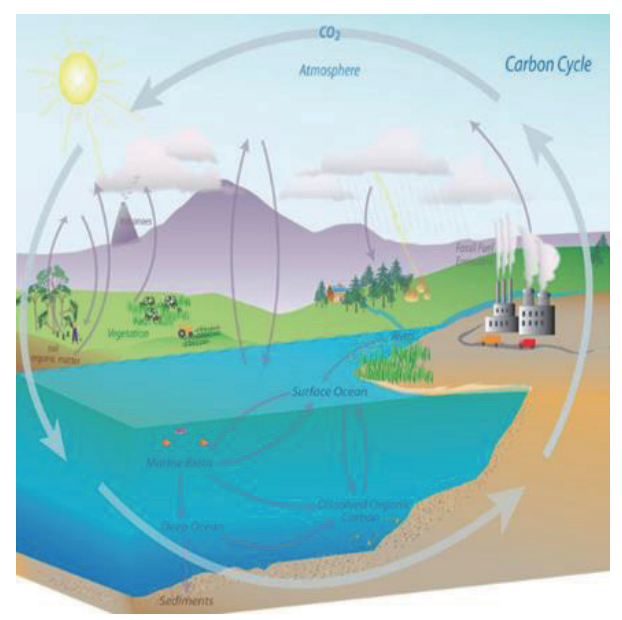

Fig. 2. (Color online) Example of carbon cycle model. $^{(20)}$ 


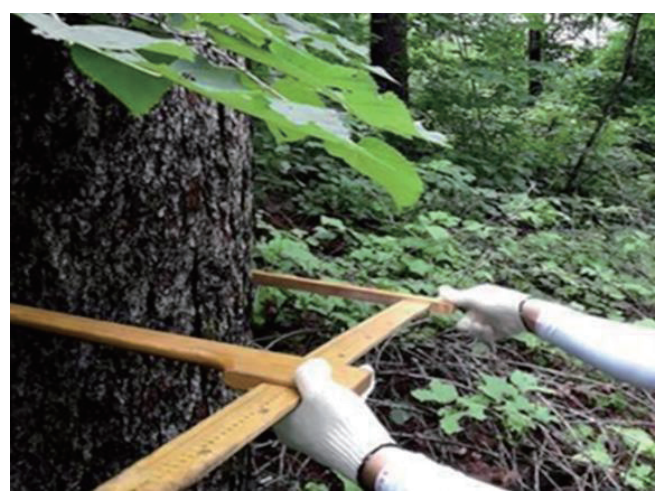

Fig. 3. (Color online) Traditional DBH measurement. ${ }^{(21)}$

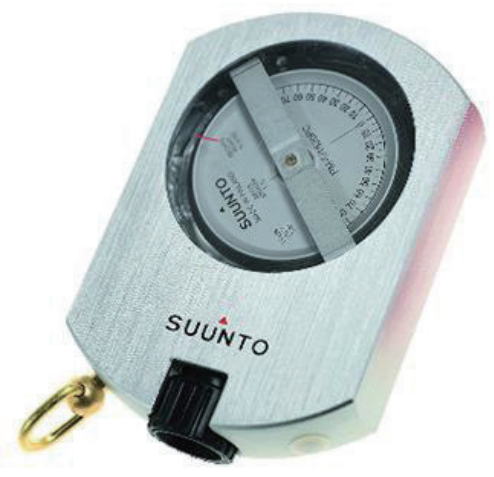

Fig. 4. (Color online) Clinometer. ${ }^{(22)}$

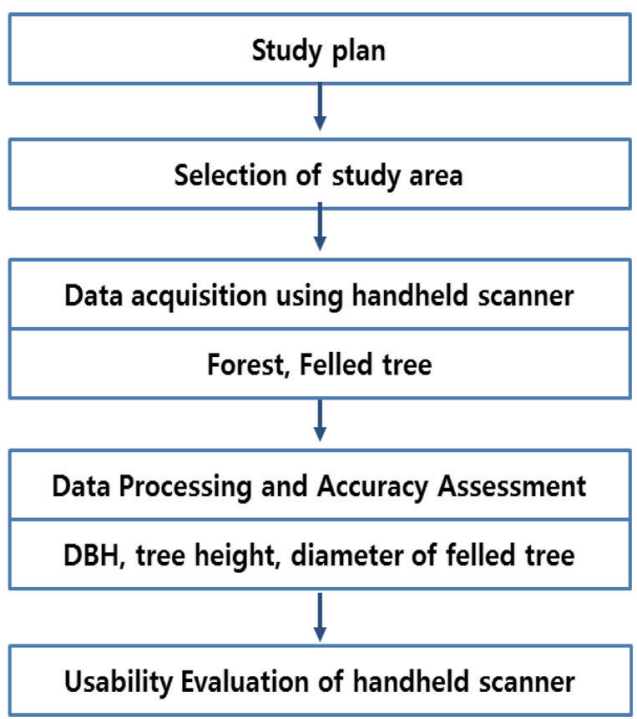

Fig. 5. Study flow.

is indirectly measured using a clinometer to the tip of the neck in $10 \mathrm{~cm}$ increments, and this method also has a high probability of error. Figure 4 shows a clinometer.

As an emerging technology, 3D laser scanning, has been introduced in the field of forestry. However, there is a lack of research on measurement in the forest sector by this method. In this study, forestry research using a 3D laser scanner was conducted to promote the innovation and application of this emerging technology. A 3D laser scanner was used to measure DBH and tree height. The geometric information obtained from a 3D laser scanner is actively used in reverse engineering and quality inspection in various industries, and it is expected to be used as a new technology for tree management among the mobile technology trends in the field of forestry. ${ }^{(23)}$ In this study, we obtained data on forests by measuring DBH and tree height using a handheld scanner. We also obtained data on felled trees, performed software measurements, and compared the results of such measurements with those obtained using calipers. Figure 5 shows the study flow. 


\section{Data Acquisition and Processing}

In this study, an experimental forest located in the Suwon area was selected as the study site. The area was chosen for research because of its well-managed forest, easy access, and the availability of felled trees to measure DBH and tree height. Figure 6 shows the study area.

GEOSLAM Horizon was used to acquire the data on the study area. This is a handheld 3D laser scanner that is equipped with an inertial measurement unit (IMU). This equipment acquires data as the user walks around, so it can acquire data quickly. Also, it can generate automatically registered point clouds using simultaneous localization and mapping (SLAM) technology. Figure 7 shows the shape of the equipment and Table 1 lists its specifications.

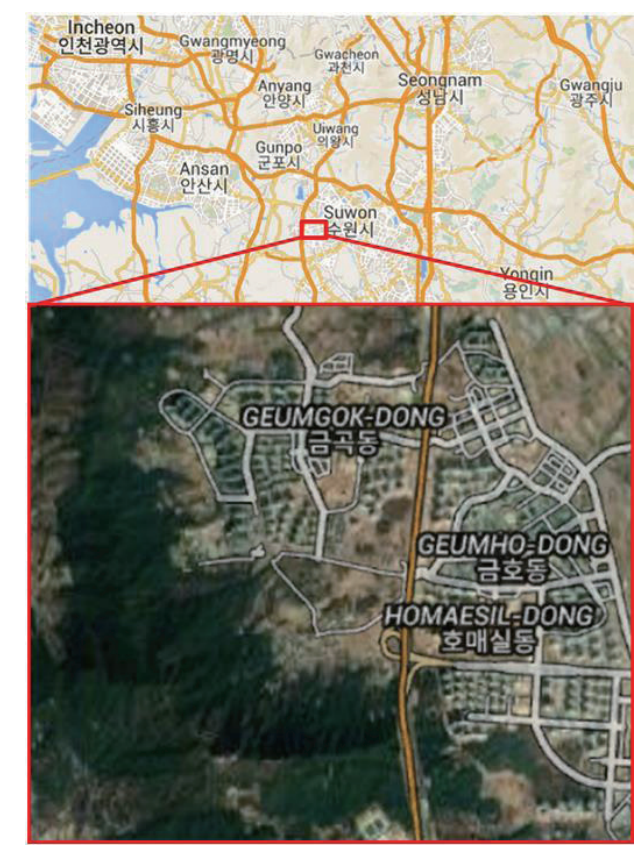

Fig. 6. (Color online) Study area.

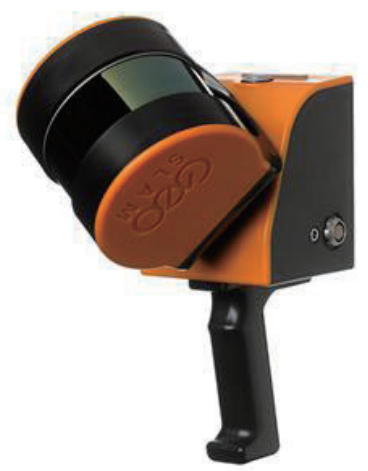

Fig. 7. (Color online) GEOSLAM Horizon. ${ }^{(24)}$
Table 1

Specifications of GEOSLAM Horizon. ${ }^{(24)}$

\begin{tabular}{lc}
\hline Item & Description \\
\hline Maximum range & $100 \mathrm{~m}$ \\
Data acquisition rate & 300000 points $/ \mathrm{s}$ \\
Resolution & $0.625^{\circ}$ horizontal, $1.8^{\circ}$ vertical \\
Angular FOV & $270^{\circ} \times 260^{\circ}$ \\
Supply voltage & $12 \mathrm{~V} \mathrm{DC}$ \\
Weight & $1.3 \mathrm{~kg}$ \\
Operating temperature & $0-50^{\circ} \mathrm{C}$ \\
Operating humidity & $<85 \% \mathrm{RH}$ \\
\hline
\end{tabular}


The data acquired using GEOSLAM Horizon are 3D data in the form of a point cloud. Continuously acquired data are automatically registered using SLAM technology. Data were acquired from forest areas and felled trees in this study. Figures 8 and 9 show data acquisition. Figures 10 and 11 show the data acquired using GEOSLAM Horizon.

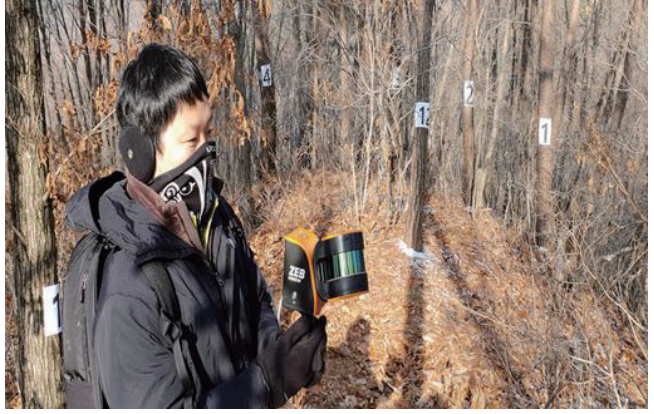

Fig. 8. (Color online) Data acquisition in forest area.

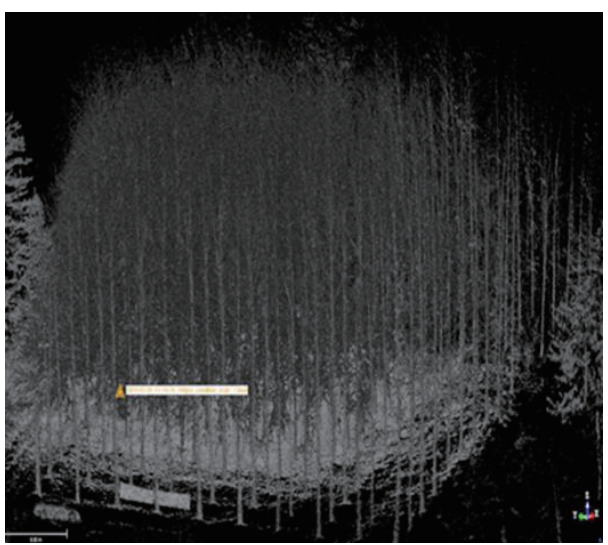

(a)

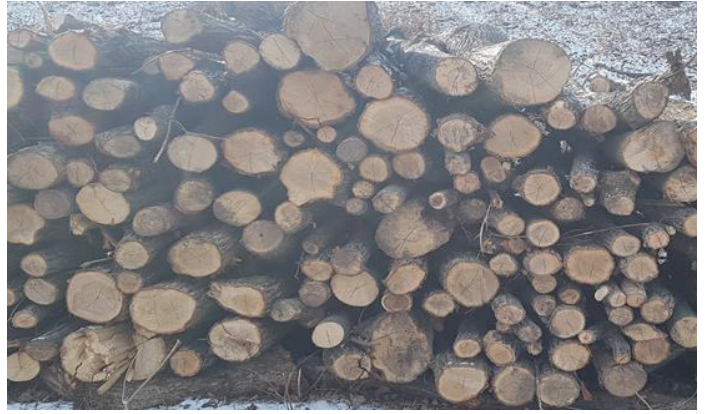

Fig. 9. (Color online) Data acquisition of felled trees.

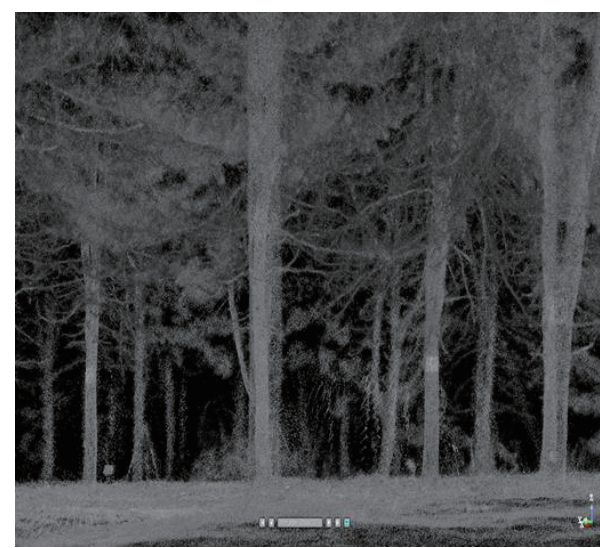

(b)

Fig. 10. Forest area data. (a) Entire data. (b) Zoom in on part of data.

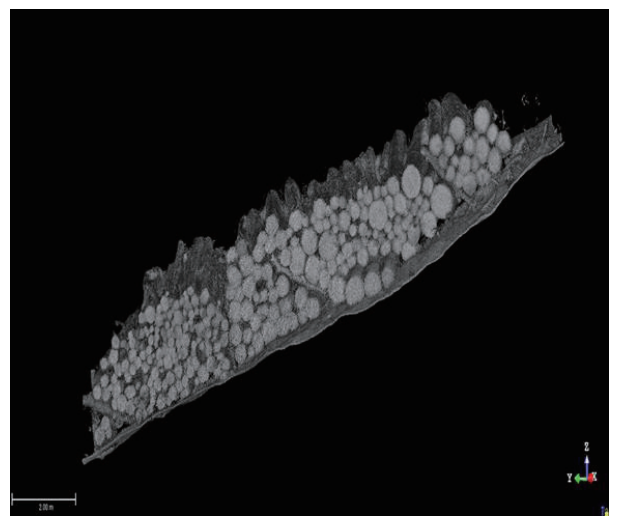

Fig. 11. Data of felled trees. 
A point cloud in the LAS format was generated through data processing using GEOSLAM Hub software. The main functions of the software are data processing, adjustment, and export. Table 2 shows the features of the software.

Data processing results were exported to the LAS format, which is a format for general point cloud data, meaning that it can be processed in many general-purpose software programs.

\section{Usability Assessment}

In this study, DBH and tree height were measured using point cloud data generated through processing to evaluate the utility of forest area measurement using a handheld scanner. DBH and tree height were measured using Trimble Real Works (TRW) software, which can edit a point cloud. For this purpose, the ground and trees were separated from the point cloud data. The extracted ground is shown in Fig. 12, the extracted trees are shown in Fig. 13, and the result of separating the trees from the ground is shown in Fig. 14.

The measured values of DBH and tree height were compared with caliper and total station values, respectively. For DBH measurements using the point cloud, the trees were extracted up to a height of $1.2 \mathrm{~m}$, from which their DBH was measured. Figures 15 and 16 show the measurements of DBH and tree height. Table 3 shows a comparison of DBH and tree height for each method.

Table 2

Software features.

\begin{tabular}{lr}
\hline Item & Feature \\
\hline Adjustment & Georeferencing for improved accuracy of scan data \\
Processing & Automated data processing, point cloud generation \\
View & Extract coordinates, dimensions, and areas and highlight important elements \\
Export & Smoothed and decimated data export (LAS and E57 format data) \\
\hline
\end{tabular}

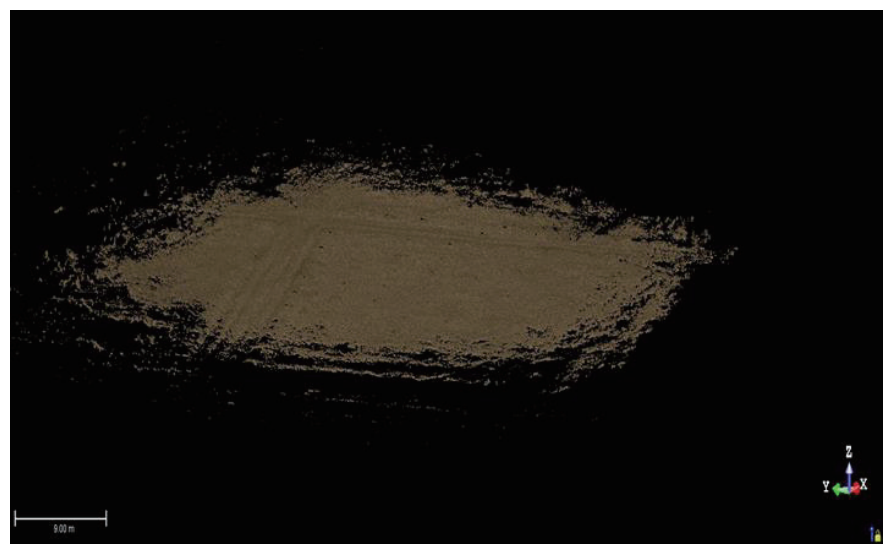

Fig. 12. (Color online) Extracted ground. 


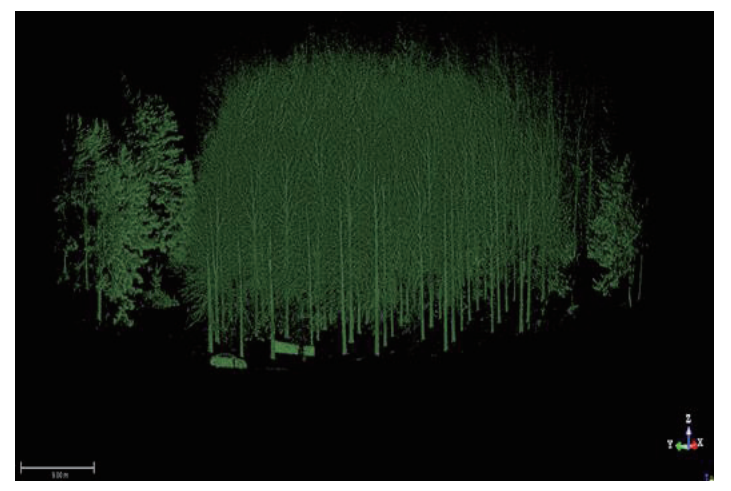

Fig. 13. (Color online) Extracted trees.

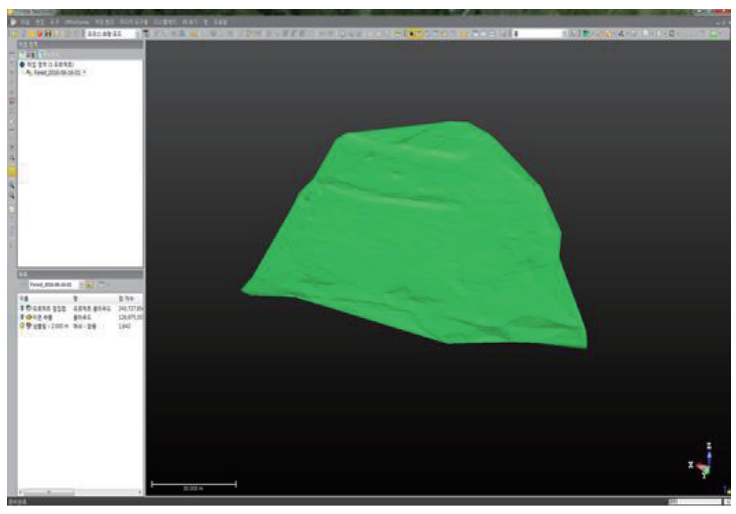

(a)

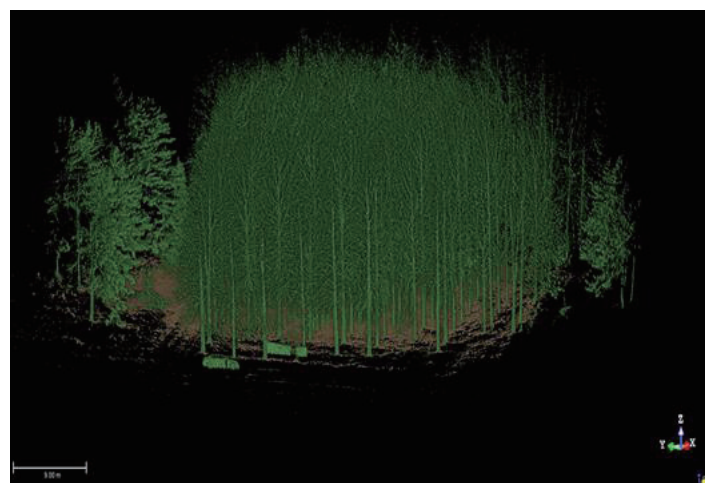

Fig. 14. (Color online) Result of separating trees from ground.

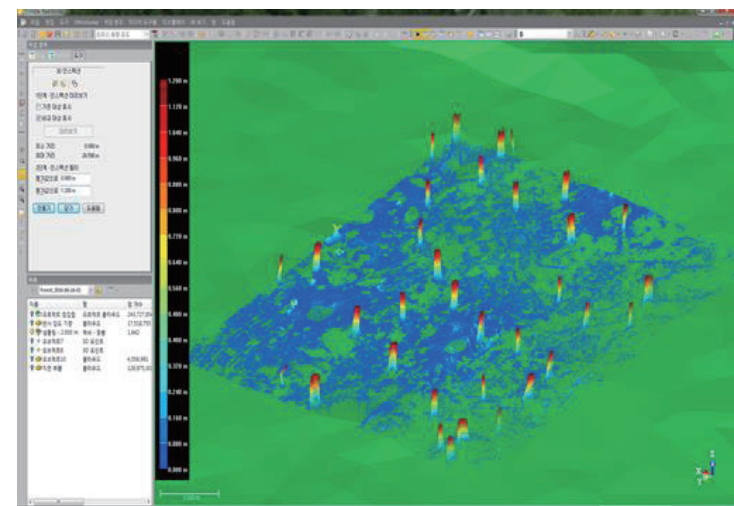

(b)

Fig. 15. (Color online) Tree extraction for DBH measurement. (a) Modeling of ground. (b) Extraction up to height of $1.2 \mathrm{~m}$.

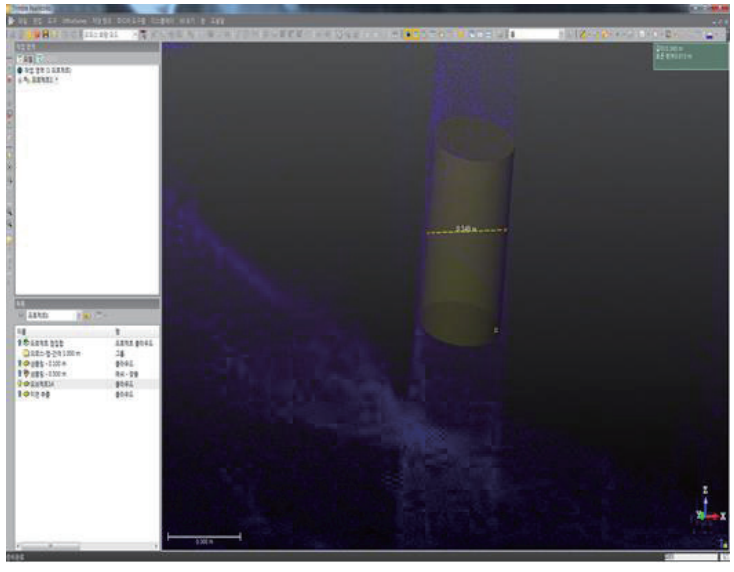

(a)

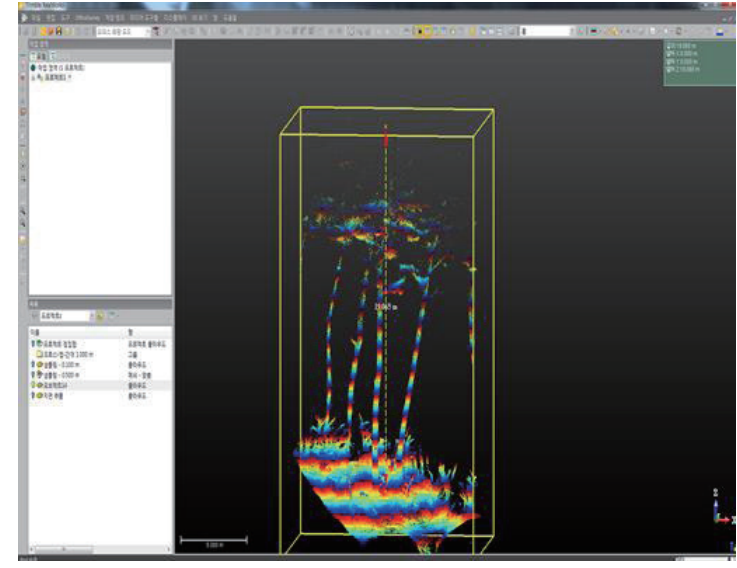

(b)

Fig. 16. (Color online) Measurements of DBH and tree height. (a) DBH. (b) Tree height. 
Table 3

Comparison of DBH and tree height.

\begin{tabular}{|c|c|c|c|c|c|c|c|}
\hline \multirow[b]{2}{*}{ No. } & \multicolumn{3}{|c|}{$\mathrm{DBH}(\mathrm{m})$} & \multirow[b]{2}{*}{ No. } & \multicolumn{3}{|c|}{ Tree Height (m) } \\
\hline & Scanner & $\begin{array}{l}\text { Reference } \\
\text { (calipers) }\end{array}$ & Deviation & & Scanner & $\begin{array}{l}\text { Reference } \\
\text { (total station) }\end{array}$ & Deviation \\
\hline 1 & 0.291 & 0.28 & -0.011 & 1 & 20.54 & 20.62 & -0.08 \\
\hline 2 & 0.303 & 0.29 & -0.013 & 2 & 21.87 & 21.96 & -0.09 \\
\hline 3 & 0.288 & 0.25 & -0.038 & 3 & 20.62 & 20.59 & 0.03 \\
\hline 4 & 0.279 & 0.27 & -0.009 & 4 & 16.66 & 16.74 & -0.08 \\
\hline 5 & 0.265 & 0.25 & -0.015 & 5 & 20.64 & 20.68 & -0.04 \\
\hline 6 & 0.286 & 0.27 & -0.016 & 6 & 20.05 & 19.98 & 0.07 \\
\hline 7 & 0.331 & 0.31 & -0.021 & 7 & 20.92 & 20.84 & 0.08 \\
\hline 8 & 0.262 & 0.24 & -0.022 & 8 & 20.24 & 20.26 & -0.02 \\
\hline 9 & 0.331 & 0.3 & -0.031 & 9 & 21.11 & 21.2 & -0.09 \\
\hline 10 & 0.254 & 0.23 & -0.024 & 10 & 19.53 & 19.61 & -0.08 \\
\hline 11 & 0.319 & 0.3 & -0.019 & 11 & 20.09 & 20.15 & -0.06 \\
\hline 12 & 0.29 & 0.27 & -0.02 & 12 & 20.25 & 20.19 & 0.06 \\
\hline 13 & 0.278 & 0.25 & -0.028 & 13 & 19.6 & 19.52 & 0.08 \\
\hline 14 & 0.284 & 0.25 & -0.034 & 14 & 21.19 & 21.25 & -0.06 \\
\hline 15 & 0.311 & 0.28 & -0.031 & 15 & 21.05 & 21.12 & -0.07 \\
\hline 16 & 0.263 & 0.24 & -0.023 & 16 & 20.56 & 20.65 & -0.09 \\
\hline 17 & 0.295 & 0.27 & -0.025 & 17 & 21.3 & 21.21 & 0.09 \\
\hline 18 & 0.284 & 0.26 & -0.024 & 18 & 20.42 & 20.36 & 0.06 \\
\hline 19 & 0.234 & 0.22 & -0.014 & 19 & 18.51 & 18.59 & -0.08 \\
\hline 20 & 0.325 & 0.31 & -0.015 & 20 & 19.63 & 19.64 & -0.01 \\
\hline 21 & 0.384 & 0.36 & -0.024 & 21 & 20.75 & 20.67 & 0.08 \\
\hline 22 & 0.39 & 0.36 & -0.03 & 22 & 20.13 & 20.18 & -0.05 \\
\hline 23 & 0.324 & 0.29 & -0.034 & 23 & 17.73 & 17.67 & 0.06 \\
\hline
\end{tabular}

As shown in Table 3, the DBH measurements showed a deviation of less than $4 \mathrm{~cm}$ from the caliper measurements. Since the study site is an experimental forest, accurate DBH measurements can be made using calipers. These results indicate that DBH can be measured using a handheld scanner. This method can reduce the errors that occur when using calipers to measure trees with irregular shapes in real forests. Also, measuring a tree diameter at a height of $1.2 \mathrm{~m}$ is difficult in the field, so using a handheld scanner will improve work efficiency. The tree heights were within $10 \mathrm{~cm}$ of the reference values. Although the reference values were measured using the total station for accurate measurement, an error is likely to occur when using a clinometer in the field, and tree height measurement using a handheld scanner may improve the measurement accuracy. In this study, the diameters of felled trees were additionally measured and compared with the values measured using calipers and the handheld scanner data. Figure 17 shows the diameters of the felled trees obtained using TRW software and Table 4 shows a comparison of the felled tree diameters.

The diameters of the felled trees measured using the scanner showed a difference of within $4 \mathrm{~cm}$ from the reference values. This slight difference from the values measured using calipers or tape may be due to the noise of the point cloud. If further research is performed to reduce noise and automate the measurement, a scanner-based method may be used to measure the 


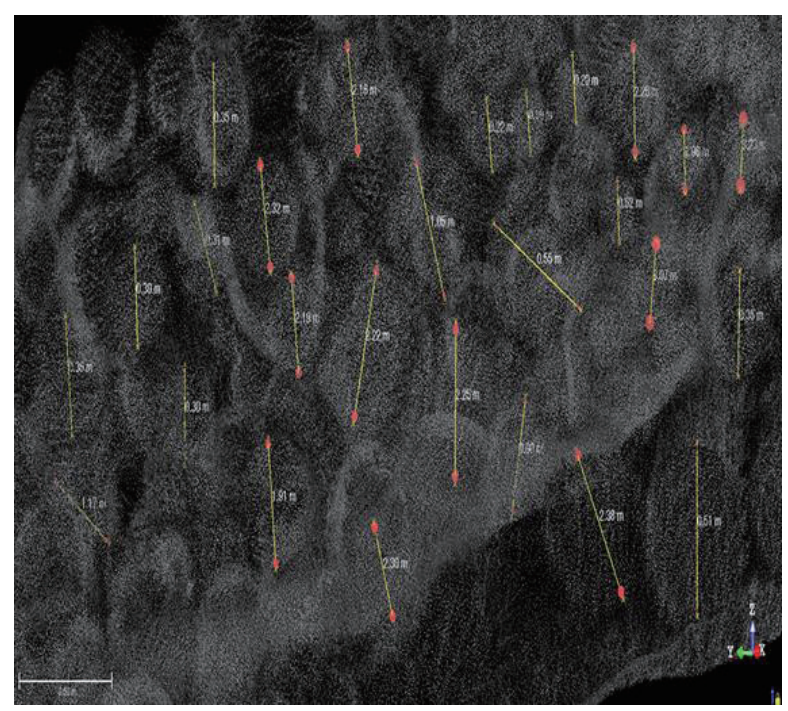

Fig. 17. (Color online) Diameters of felled trees obtained using TRW software.

Table 4

Comparison of diameters of felled trees.

\begin{tabular}{|c|c|c|c|c|c|c|c|}
\hline No. & Scanner (m) & Calipers (m) & Deviation (m) & No. & Scanner $(\mathrm{m})$ & Calipers (m) & Deviation (m) \\
\hline 1 & 0.55 & 0.53 & 0.02 & 15 & 0.9 & 0.92 & -0.02 \\
\hline 2 & 1.05 & 1.01 & 0.04 & 16 & 0.25 & 0.25 & 0 \\
\hline 3 & 0.38 & 0.38 & 0 & 17 & 0.51 & 0.52 & -0.01 \\
\hline 4 & 0.22 & 0.2 & 0.02 & 18 & 0.35 & 0.32 & 0.03 \\
\hline 5 & 0.32 & 0.31 & 0.01 & 19 & 0.18 & 0.17 & 0.01 \\
\hline 6 & 0.35 & 0.37 & -0.02 & 20 & 0.19 & 0.18 & 0.01 \\
\hline 7 & 0.91 & 0.92 & -0.01 & 21 & 0.19 & 0.2 & -0.01 \\
\hline 8 & 0.3 & 0.28 & 0.02 & 22 & 0.22 & 0.22 & 0 \\
\hline 9 & 0.3 & 0.29 & 0.01 & 23 & 0.2 & 0.23 & -0.03 \\
\hline 10 & 0.31 & 0.32 & -0.01 & 24 & 0.19 & 0.18 & 0.01 \\
\hline 11 & 0.36 & 0.35 & 0.01 & 25 & 0.52 & 0.53 & -0.01 \\
\hline 12 & 0.18 & 0.17 & 0.01 & 26 & 0.33 & 0.32 & 0.01 \\
\hline 13 & 0.23 & 0.23 & 0 & 27 & 0.32 & 0.33 & -0.01 \\
\hline 14 & 0.25 & 0.25 & 0 & & & & \\
\hline
\end{tabular}

diameters of felled trees. Using a scanner will greatly increase the work efficiency compared with using calipers or a tape. Figure 18 shows the deviation of values measured using a scanner.

The measurement of $\mathrm{DBH}$, tree height, and felled trees using a handheld scanner will not only increase the accuracy but also improve the work efficiency compared with that using conventional calipers and a clinometer. Conventional methods measure and record DBH and tree height separately, but the method using a scanner is effective because the results can be calculated by a single measurement and office work using software. If software is developed to automate the measurement of the $\mathrm{DBH}$, tree height, and diameter of felled trees, many tasks can be automated as shown in Table 5, which will greatly improve the efficiency of forestry tasks. 


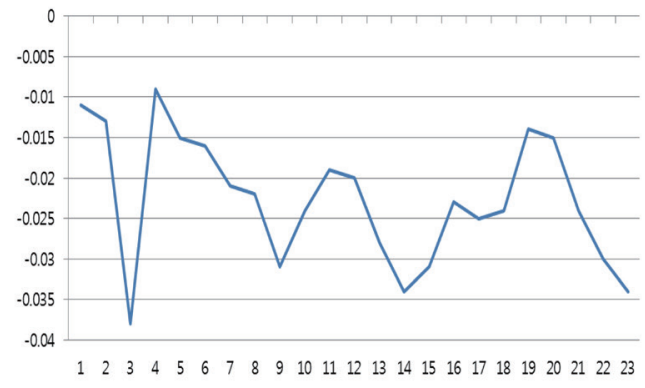

(a)

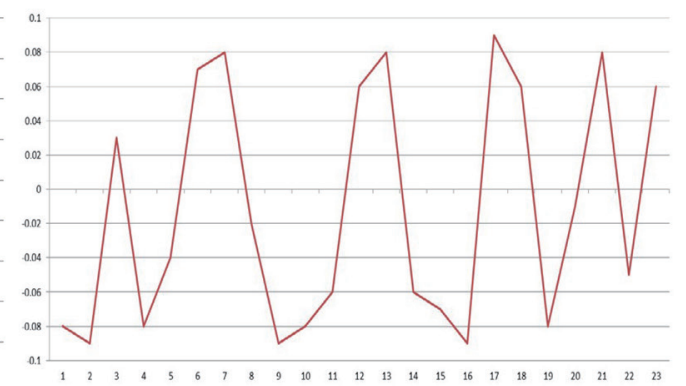

(b)

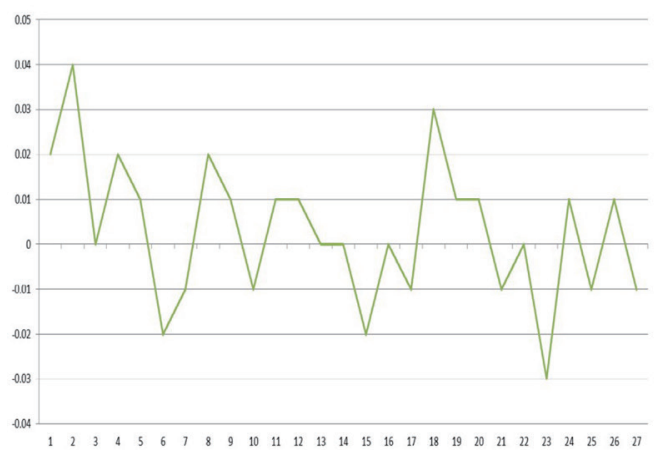

(c)

Fig. 18. (Color online) Deviation of values measured using scanner. (a) DBH. (b) Tree height. (c) Diameter of felled tree.

Table 5

Comparison of diameters of felled trees.

\begin{tabular}{llcc}
\hline & Task & \multicolumn{1}{c}{ Description } & Remarks \\
\hline \multirow{2}{*}{ DBH } & Field measurement & $\begin{array}{c}\text { Area measurement with handheld scanner } \\
\text { instead of manual measurement of each object }\end{array}$ & Improve efficiency \\
\cline { 2 - 4 } Tree height & Create report & $\begin{array}{c}\text { Automatically measure diameter } \\
\text { at } 1.2 \text { m height from ground }\end{array}$ & Automation \\
\cline { 2 - 4 } & Field measurement & $\begin{array}{c}\text { Area measurement with handheld scanner } \\
\text { instead of manual measurement of each object }\end{array}$ & Improve efficiency \\
\hline \multirow{2}{*}{$\begin{array}{l}\text { Diameter of } \\
\text { felled tree }\end{array}$} & Field measurement & $\begin{array}{c}\text { Area measurement with handheld scanner } \\
\text { instead of manual measurement of each object }\end{array}$ & Improve efficiency \\
\cline { 2 - 4 } & Create report & $\begin{array}{c}\text { Automatic generation of software } \\
\text { to replace handwritten reports }\end{array}$ & Automation \\
\hline
\end{tabular}

\section{Conclusions}

In this study, forestry research using a 3D laser scanner was conducted to promote innovation and the application of this emerging technology. A 3D laser scanner was used to measure DBH and tree height. Data on the forest studied were obtained using a handheld scanner. Software measurements were also performed on felled trees to obtain data, which were compared with those obtained using calipers. The DBH measurements showed a deviation of less than $4 \mathrm{~cm}$ compared 
with caliper measurements. These results indicate that DBH can be measured using a handheld scanner. The tree heights were within $10 \mathrm{~cm}$ of the reference values. Although the reference values were obtained by measurement using the total station for accurate measurement, an error is likely to occur when using a clinometer in the field, and tree height measurement using a handheld scanner may improve the measurement accuracy. The diameters of felled trees measured using a scanner were within $4 \mathrm{~cm}$ from the reference values. The slight difference from the values measured using calipers or a tape may be due to the noise of the point cloud. If further research is performed to reduce noise and automate the measurement, a scanner-based method may be used to measure the diameters of felled trees. The measurement of DBH, tree height, and felled trees using a handheld scanner will not only increase the accuracy but also improve the work efficiency compared with the use of conventional calipers and a clinometer. Conventional methods measure and record DBH and tree height separately, but the method of using a scanner is effective because the results can be calculated by a single measurement and office work using software.

\section{Acknowledgments}

This research was supported by the Basic Science Research Program through the National Research Foundation of Korea (NRF) funded by the Ministry of Science and ICT (No. NRF2018R1C1B6004021).

\section{References}

1 C. Liu, Y. Xing, J. Duanmu, and X. Tian: Remote Sens. 10 (2018) 1. https://doi.org/10.3390/rs10040513

2 H. C. Yun and J. S. Lee: J. Korea Academia-Industrial Cooperation Soc. 19 (2018) 734. https://doi.org/10.5762/ KAIS.2018.19.12.734

3 Y. Yin, Y. Xu, W. Xu, M. Gao, L. Yu, and Y. Pei: Entropy 19 (2017) 358 https://doi.org/ 10.3390/e19070358

4 S. H. Ju, S. H. Yoon, S. Y. Park, and J. Heo: J. Korean Soc. Surv. Geod. Photogramm. Cartography 36 (2018) 443.

5 J. H. Oh, Y. J. Jang, and C. N. Lee: J. Korean Soc. Surv. Geod. Photogramm. Cartography 36 (2018) 565. https://doi.org/10.7848/ksgpc.2019.37.4.243

6 J. K. Park and D. Y. Um: J. Korea Academia-Industrial Cooperation Soc. 19 (2018) 155. https://doi.org/10.5762/ KAIS.2018.19.3.155

7 Z. Yu, J. Yu, C. Xiang, J. Fan, and D. Tao: IEEE Trans. Neural Networks Learn. Syst. 29 (2018) 5947.

8 H. S. Moon and W. S. Lee: J. Korea Academia-Industrial Cooperation Soc. 17 (2016) 427. https://doi. org/10.5762/KAIS.2016.17.12.427

9 G. Jia, G. Han, J. Jiang, S. Chan, and Y. Liu: Pers. Ubiquitous Comput. 22 (2018) 561. https://doi.org/10.1007/ s00779-018-1118-5

10 K. W. Lee and J. K. Park: J. Korea Academia-Industrial Cooperation Soc. 20 (2019) 440. https://doi. org/10.5762/KAIS.2019.20.1.440

11 B. G. Lee: J. Korean Earth Sci. Soc. 39 (2018) 46. https://doi.org/10.5467/JKESS.2018.39.1.46

12 Y. Yin, S. Aihua, G. Min, Y. Xu, and W. Shuoping: Int. J. Software Eng. Knowledge Eng. 26 (2016) 611. https://doi.org/10.1142/S0218194016400040

13 D. K. Lee, K. D. Kim, S. R. Yang, and H. J. Lee: J. Korea Soc. Geospatial Inf. Syst. 27 (2019) 31. https://doi. org/ 10.7319/kogsis.2019.27.2.031

14 J. H. Song, J. O. Kwon, and C. W. Yun: J. Korean Soc. Environ. Ecology 33 (2019) 28. https://doi.org/10.13047/ KJEE.2019.33.1.28

15 D. S. Ko and J. H. Choi: Int. J. Grid Distributed Comput. 10 (2017) 1. https://doi.org/10.14257/ ijgdc.2017.10.12.01

16 J. W. Lim, G. E. Park, N. H. Moon, G. H. Moon, and M. Y. Shin: J. Korean Soc. Forest Sci. 106 (2017) 249. https://doi.org/10.14578.jkfs.2017.106.2.249 
17 Y. Yin, F. Yu, Y. Xu, L. Yu, and J. Mu: Sensors 17 (2017) 2059. https://doi.org/10.3390/s17092059

18 J. K. Byun, J. K. Shin, J. E. Yun, H. G. Kim, S. H. Oh, and D. K. Kim: J. Agric. Life Sci. 1 (2017) 77. https:// doi.org/10.14397/jals.2017.51.1.77

19 J. Yu, B. Zhang, Z. Kuang, D. Lin, and J. Fan: IEEE Trans. Inf. Forensics Secur. 12 (2017) 1005. https://doi. org/10.1109/TIFS.2016.2636090

20 National Oceanic and Atmospheric Administration: https://www.noaa.gov/ (accessed January 2020).

21 Korea Forest Service: http://english.forest.go.kr/newkfsweb/ (accessed January 2020).

22 Suunto: https://www.suunto.com/ko-kr/ (accessed January 2020).

23 J. K. Park and K. Y. Jung: J. Korea Academia-Industrial Cooperation Soc. 19 (2018) 602.

24 GeoSLAM: https://geoslam.com/ (accessed January 2020).

\section{About the Authors}

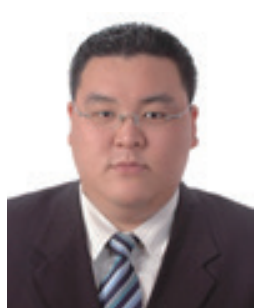

Joon Kyu Park is currently a professor in the Department of Civil Engineering at Seoil University. He received his B.S., M.S., and Ph.D. degrees in civil engineering from Chungnam National University, Korea, in 2001, 2003, and 2008, respectively. His research interests are in the areas of GPS and geospatial information engineering. (jkpark@seoil.ac.kr)

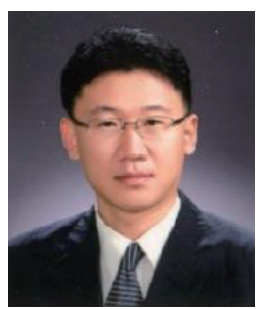

Dae Yong Um is currently a professor in the Department of Civil Engineering at Korea National University of Transportation. He received his B.S., M.S., and Ph.D. degrees in civil engineering from Chungnam National University, Korea, in 1997, 1999, and 2004, respectively. His research interests are in the areas of geospatial information engineering and photogrammetry.

(dyum@ut.ac.kr) 